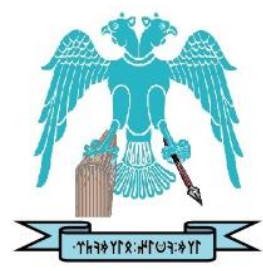

JOURNAL OF ENERGY SYSTEMS

$2021,5(1)$

\title{
Low density hemp shive particleboards for latent thermal energy storage performance
}

Edgars Kirilovs

RTU, Faculty of Materials Science and Applied Chemistry, Institute of Design Technologies, Riga, Latvia, edgars.kirilovs@rtu.lv

Inga Zotova

RTU, Faculty of Materials Science and Applied Chemistry, Institute of Design Technologies, Riga, Latvia, inga.zotova@rtu.lv

Silvija Kukle

RTU, Faculty of Materials Science and Applied Chemistry, Institute of Design Technologies, Riga, Latvia, silvija.kukle@ rtu.lv

Kārlis Pugovičs (D)

Forest and Wood Products Research and Development Institute, Jelgava, Latvia, karlis.pugovics@e-koks.lv

$\begin{array}{rr}\text { Submitted: } & 18.02 .2020 \\ \text { Accepted: } & 07.01 .2021 \\ \text { Published: } & 31.03 .2021\end{array}$

\begin{abstract}
Over the past few decades, climate change and the search for renewable energy sources have become hot topics within the research community. About $30 \%$ of the world's energy consumption is in the heating and cooling sector of residential buildings. Such materials can reduce the temperature variations, leading to an improvement in human comfort and decreasing at the same time the energy consumption of buildings. This paper assesses the integration of a microencapsulated phase change material (PCMs) with organic composite phase change as the core material and melamine-formaldehyde as the shell in hemp shive intended for building indoor wallboard. Paraffin waxes are cost-effective and have moderate thermal energy storage density but low thermal conductivity and, hence, require large surface area. Commercial manufactured organic PCM-S28 with a $25-29^{\circ} \mathrm{C}$ melting point received from MikroCaps Ltd. (Slovenia) has been used. The experimental boards were made using cold pressing technology and with $10 \%$ Kleiberit Urea Formaldehyde resin (UF) glue as a binding agent. The experimental boards were made $25 \mathrm{~mm}$ thick with a density of $310 \pm 20 \mathrm{~kg} / \mathrm{m} 3$ that qualify them as low-density boards. By adding $5 \%$ nanocapsules during the board manufacturing process, the heat capacity is increased by $28 \%$.
\end{abstract}

Keywords: Energy storage, Hemp shive, Phase change materials, Phase transition heat, Specific heat capacity

Kirilovs, E., Zotova, I., Kukle, S., \& Pugovičs, K, Low density hemp shive particleboards for latent
Cite this paper as: $10.30521 /$ jes. 805791

(C) 2021 Published by peer-reviewed open access scientific journal, JES at DergiPark (https://dergipark.org.tr/en/pub/jes) 


\section{INTRODUCTION}

High interest for energy consumption has occurred, therefore the technologies keep developing and the range of useful solutions to improve the level of comfort increases. European Union (EU) and the whole world faces climate change caused by the emissions of greenhouse gases [1,2]. According to the action plan developed by United Nations (UN) "Agenda 21" regarding sustainable development, environmentally friendly technologies are considered those that protect and reduce the adverse environmental impact throughout the material life cycle- from the extraction of raw materials and ending with the product / material further use or recycling. The building sector is responsible for approximately two-third of halocarbon and approximately 25-30\% of black carbon emissions [3, 4, 5]. Renewable raw materials, including natural fiber sources, are the future of storage resources with a variety of positive effects on both the planet ecosystem and the living and working environment, and the energy consumption of delivering the required functionality. Natural fibres are selected to be used in ecological buildings where the choice of materials is based on such parameters as recyclable, renewable raw materials, and low-resource production techniques $[6,7,8,9]$. In addition to the traditional methods of hemp stalk separation into fibres and shives, the utilization of the whole straw has become relevant for several years already. The described supply chain for wet preserved hemp raw materials is based on long term research activities at Leibniz Institute of Agricultural Engineering and Bioeconomy (ATB) in Potsdam (Germany) $[10,11]$. There are done studies to analyze different natural resources usability in board materials $[12,13,14]$. One of the important targets is to get good parameters for thermal specific heat capacity- to reach high utility there are used innovative technologies-nano encapsulated phase change material (PCMs). Phase change materials are recognized as an effective way to improve building's energy management. Such materials are able to store a large amount of energy due to a transition of phase that is most frequently the solid/liquid one. This can enhance the building thermal mass and thus leads to energy efficiency. Studies about phase-change material (PCM) as latent thermal energy storage have been made for more than 50 years, but the low energy prices and high raw material costs did not motivate to start the product design. Currently the situation has significantly changed since the decreasing PCM costs and increasing energy prices, they are used as latent thermal energy storage for the indoor microclimate self-regulation depending on the environmental temperature $[15,16,17,18$, 19]. The PCM can be incorporated in construction materials and elements by direct incorporation, immersion, encapsulation, shape-stabilization and form stable composite PCMs [20, 21, 22, 23, 24].

\section{MATERIALS AND METHODS}

\subsection{Materials}

To produce wall board material there are used three different components due to following criteria: Functional concordance; impact on the environment (extraction, manufacturing, use); local availability. Hemp (Cannabis sativa L.) was grown at the experimental plot of Agriculture Science Center of Latgale (ASCL) in 2017. Varietie Polish Bialobrzeskie (owner: Institute of Natural Fibres \& Medicinal Plants, Poznan) has been chosen for experimental part. Industrial hemp variety Bialobrzeskie is a very promising, economically perspective cultivated plant that permits producing high harvests of hemp stems in the Latvian soil and climatic conditions, and it is also a regenerating plant to the environment. To prepare raw materials traditional technology was used. Among other European locations they have been cultivated under agricultural conditions as well in Vilani, Latvia $\left(56^{\circ} 33^{\prime} 09^{\prime \prime} \mathrm{N} 26^{\circ} 55^{\prime} 29^{\prime \prime} \mathrm{E}\right)$. The harvest was carried out August 2017 by means of a forage harvester. The phase change material microcapsule (PCMs) MikroCaps Ltd. (Slovenia) products have been selected and incorporated into the insulation wall board material prototypes. According to MikroCaps Ltd. PCM-S28 has a melting temperature of $25-29^{\circ} \mathrm{C}$, latent heat of dried microcapsules $160-185 \mathrm{~J} / \mathrm{g}, \mathrm{pH} 7.0-9.0$, density 900-970 
$\mathrm{g} / \mathrm{L}$, viscosity (at $25^{\circ} \mathrm{C}$ ) 100-500 $\mathrm{cPs}$, appearance of white a concentrated aqueous dispersion slurry, average microcapsules particles size 2-10 $\mu \mathrm{m}$, melamine-formaldehyde membrane and paraffin wax PCM type. As adhesive for the material prototype used commercial Kleiberit 862.0 Urea Formaldehyde Resins (UF) with hardener for cold pressing.

\subsection{Cold pressing technology}

Using cold pressing (template and punches) 400x400 mm samples are made. These linear dimensions are selected considering the planned test methods and the necessary samples configurations for the tests. The prototypes of the material are made based on layer method. Resin powder with hardener and water are dosed at the ratio of 2:1 according to the technical data sheet of the producer. Dosing cups are used to determine the binder components. After mixing the components stirring is carried out for at least two minutes to ensure smooth addition of the hardener. When the required homogenous mixture of binder is obtained the PCM microcapsule concentrated dispersion is added in the amount of 5\% of the starting material dry weight. The stirring of the components is being done for $300 \mathrm{sec}$ to obtain homogenous consistency. The binder is added gradually using a spray gun for shives to obtain homogenous mixture and stirring is performed with an electric mixer over a period of $300 \mathrm{sec}$. Both hemp shives and binder mixture are formed in the $400 \times 400 \mathrm{~mm}$ template. This is done in two steps: during the first step a part of the mixture is pressed to the thickness of $50 \mathrm{~mm}$, and during the second step the second part of the mixture is pressed to the thickness of $25 \mathrm{~mm}$. Template and punches form is inserted in a hydraulic press and pressed for 4 hours in $22 \pm 2^{\circ} \mathrm{C}$ under 10 bar pressure, taking into consideration the polymerization time (Fig. 1).

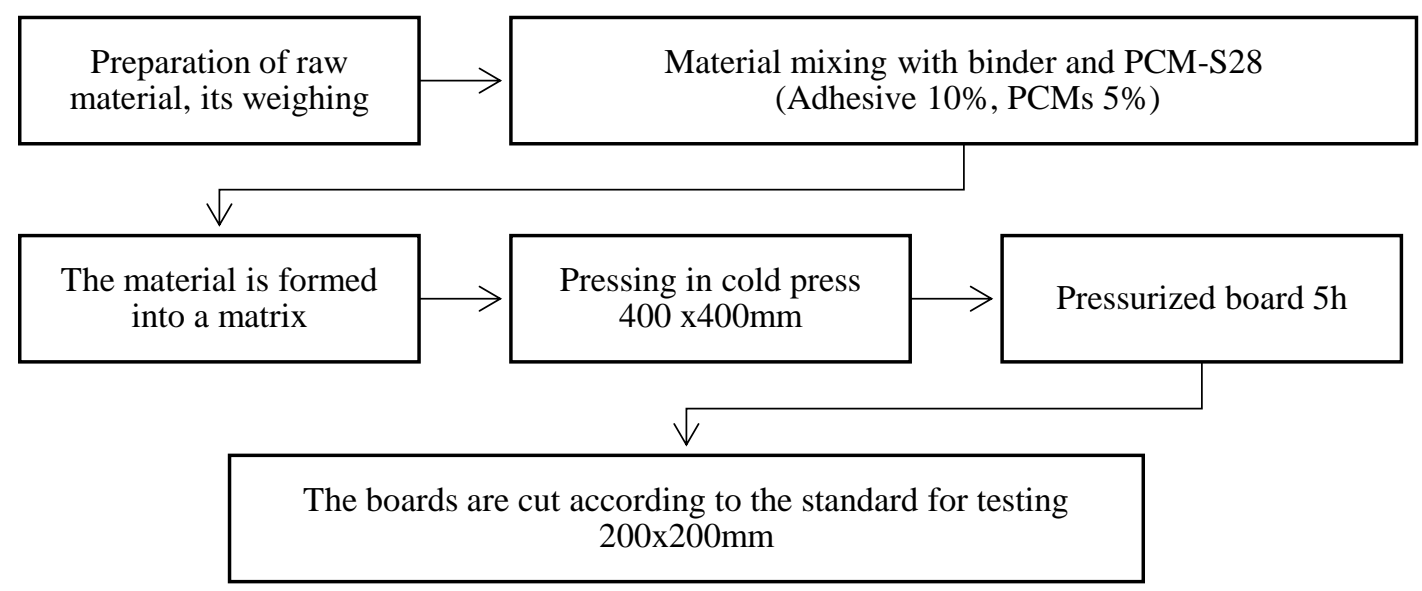

Figure 1. Preparation of the sample - schematic drawing.

\subsection{Moisture content}

Moisture content in raw material mixture materials was determined in accordance with LVS EN 322: 1993 [25] standard, using mass method. The tested material is hemp shives. Raw material is prepared in 3 separate aluminum containers, sampled from the top, middle and bottom of the bags. The dishes are numbered sequentially, weighed with a Kern digital balance EMB 600-2 (to the nearest $0.01 \mathrm{~g}$ ) and placed in an oven (Binder EU280) for 24 hours at $105 \pm 2{ }^{\circ} \mathrm{C}$ according to the standard. After the prescribed time, the samples are removed from the oven and weighed to determine the change in mass. The moisture content of the raw material is calculated from the mass of the sample before and after drying according to Eq. (1) where mass of content specimen at normal climate is defined as $m_{H}$ and mass of specimen after drying is defined as $\mathrm{m}_{0}$

$$
H=\frac{m_{H}-m_{0}}{m_{0}} \times 100
$$




\subsection{Distribution of particle masses}

All products are characterized by a particle size distribution and particle size distribution after the sieve process. With this method, it is possible to display and compare the size distribution of the components. The sieving test was determined according to the standard of LVS EN 933: 2012 [26]. It is the simplest and most widely used particle size analysis method where the smallest particles are separated from the larger ones [27]. Samples taken from the storage point immediately after drying are placed in a climatic chamber until the test. Before sifting, each sample is divided into five small samples of mass not exceeding $6 \mathrm{~g}$. Partitioning is done for better sifting and less false results. Sifting was performed in a sieve test apparatus with six different round shapes, mesh sizes of $5600 \mu \mathrm{m}, 4500 \mu \mathrm{m}, 3150 \mu \mathrm{m}, 2000$ $\mu \mathrm{m}, 1000 \mu \mathrm{m}, 500 \mu \mathrm{m}, 355 \mu \mathrm{m}, 160 \mu \mathrm{m}, 90 \mu \mathrm{m}$, made of stainless steel or brass wire mesh. The sieves are arranged in ascending order, sieving material with largest mesh size placed on the highest sieve. The sieving was performed using an interrupted cycle with a vibration time of $58 \mathrm{~s}$ and an interruption of 2 $\mathrm{s}$, the total sieving cycle of each sample lasts $540 \mathrm{~s}$. Vibration intensity is $80 \mathrm{~W} / \mathrm{m}^{2}$. After the sieving process, sieves are taken from machine one by one, each sieve is poured into a metal container, the material residues are cleaned from the sieve with a $25 \mathrm{~mm}$ wide brush, and the particles of the respective sieve are weighed. The results are expressed as a percentage of the mesh size of each sieve.

\subsection{Density}

The density of board materials is determined according to the standard LVS EN 323:2000 [28]. According to the standard, samples $50 \times 50 \mathrm{~mm}$ were cut from the pressed board and weighed on the scales "Kern" EMB 600-2 with an accuracy of $0.01 \mathrm{~g}$. The external dimensions and thickness of the sample are determined with a digital caliper KS Tools 300 with an accuracy of $0.01 \mathrm{~mm}$. To determine the thickness of the samples more accurately, measurements are made in four places (Fig. 2) and the average board thickness is calculated. Based on the obtained measurement results, the board density can be determined by the equation (2) with accuracy up to $1 \%$ correlation, where $\rho$ board density at standard humidity; $m_{w}$ mass of the test specimen; $a_{w}$ and $b_{w}$ length and width of the test specimen; $l_{w}$ thickness of the test specimen.

$$
\rho=\frac{m_{w}}{a_{w} \times b_{w} \times l_{w}}=\frac{m_{w}}{v_{w}}
$$

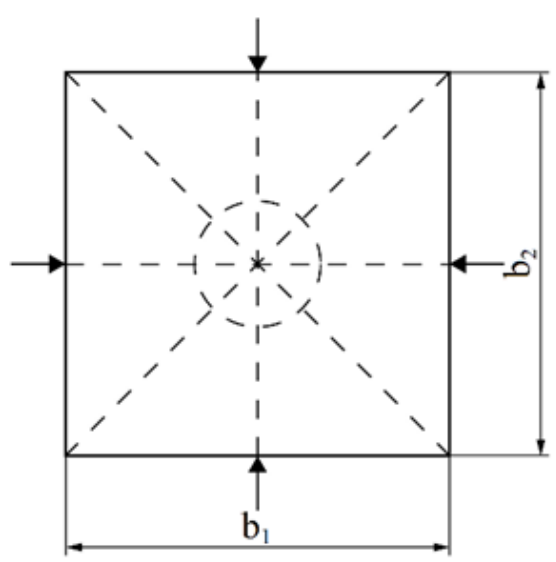

Figure 2. Scheme for determining the thickness of the sample.

\subsection{Thermal conductivity and Specific heat capacity}

The efficiency of insulation materials is described by thermal conductivity $\lambda(\mathrm{W} / \mathrm{m} \mathrm{K}$ ). The thermal conductivity is a bulk property that describes the ability of a material to transfer heat. In the following 
equation (3), thermal conductivity is the proportionality factor $k$. The distance of heat transfer is defined as $\Delta x$, which is perpendicular to area $A$. The rate of heat transferred through the material is $Q$, from temperature $T_{1}$ to temperature $\mathrm{T}_{2}$, when $T_{1}>T_{2}$ (Fig. 3).

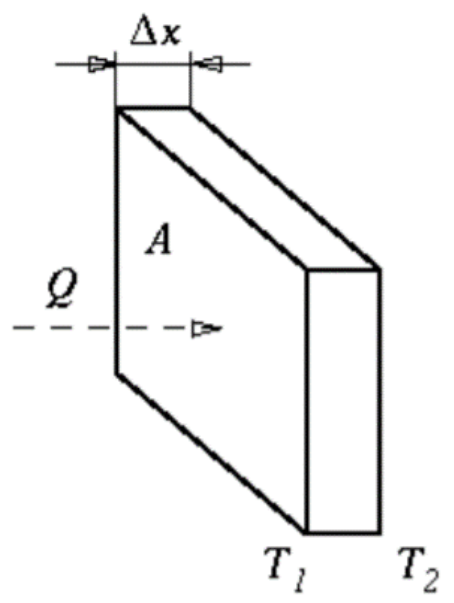

Figure 3. Scheme for determining the thermal conductivity of the sample.

One approach for the measurement of this parameter in steady-state conditions is the guarded hot plate method according LVS ISO 8302: 2001 [29]. The NETZSCH HFM 446 Lambda Small was used to determine the parameters. All samples dimension were 200x200 mm and thickness $25 \mathrm{~mm}$. The measurement principle is simple: a specimen is placed between two surfaces that are kept at constant temperatures, and the heat flow passing through the plates is registered after stationary conditions are reached; a so-called "compensations zone" with the same temperatures surrounds the flow meters to avoid heat losses in other directions. Dependence of thermal conductivity on mean temperature can be estimated by conducting the measurements with different surface temperatures [29].

$$
k=\frac{Q \Delta x}{A\left(T_{2}-T_{1}\right)}
$$

\section{RESULTS AND DISCUSSION}

\subsection{Raw material moisture content}

After 24 hours in the oven at $105 \pm 2{ }^{\circ} \mathrm{C}$, the material is removed from the oven and each sample is weighed. The mass values of the raw material sample before and after drying are given in the formula and the results obtained are summarized in Table 1.

Table 1. Raw material moisture content

\begin{tabular}{cccccc}
\hline $\begin{array}{c}\text { Raw } \\
\text { material }\end{array}$ & $\begin{array}{c}\text { Empty box } \\
(\mathrm{g})\end{array}$ & $\begin{array}{c}\text { Raw material }+ \\
\text { box }(\mathrm{g})\end{array}$ & $\begin{array}{c}\text { After 24h raw material }+ \\
\text { box }(\mathrm{g})\end{array}$ & $\begin{array}{c}\text { Moisture } \\
(\%)\end{array}$ & $\begin{array}{c}\text { Average moisture } \\
(\%)\end{array}$ \\
\hline $\begin{array}{c}\text { Hemp } \\
\text { shive }\end{array}$ & 2.78 & 21.19 & 19.65 & 7.8 & \\
$\begin{array}{c}\text { Hemp } \\
\text { shive }\end{array}$ & 2.78 & 17.88 & 16.58 & 7.8 & 7.9 \\
$\begin{array}{c}\text { Hemp } \\
\text { shive }\end{array}$ & 2.49 & 18.65 & 17.27 & 8.0 & \\
\hline
\end{tabular}


The results after the oven were calculated for raw material and the arithmetic mean was calculated. In Table 1, the average moisture content of hemp shives is shown as approximately $7.9 \%$. The determination of the moisture content of the material was performed to determine exactly whether the use of the selected binder is acceptable using these raw materials. Based on these results, it is concluded that the average moisture content of the materials is $8 \pm 2 \%$ that corresponds to the moisture content of the adhesive material specified by the binder manufacturer.

\subsection{Distribution of particle masses}

The nine sieves used for the sieving enabled us to determine the distribution of the particle masses according to the dimensions of the sieve's eye (Fig. 4). The largest proportion is fractions exceeding $2000-3150 \mu \mathrm{m}-25 \%$ of the total amount (Fig. 5). Less than $20 \%$ of the hemp shive material has fractions larger than $5600 \mu \mathrm{m}$. The fractions ranging from $500-1000 \mu \mathrm{m}$ make up to $17.7 \%$. Fraction size below $500 \mu \mathrm{m}$ (the fine and dust content of the raw material) is about 3.5\%. Fractions of this size affect the mechanical properties of the board, because mixing the material with the binder attracts most of the adhesive and the larger fractions get a smaller amount of binder. So, it was concluded to separate fractions of this size from the total mass before mixing with binder.

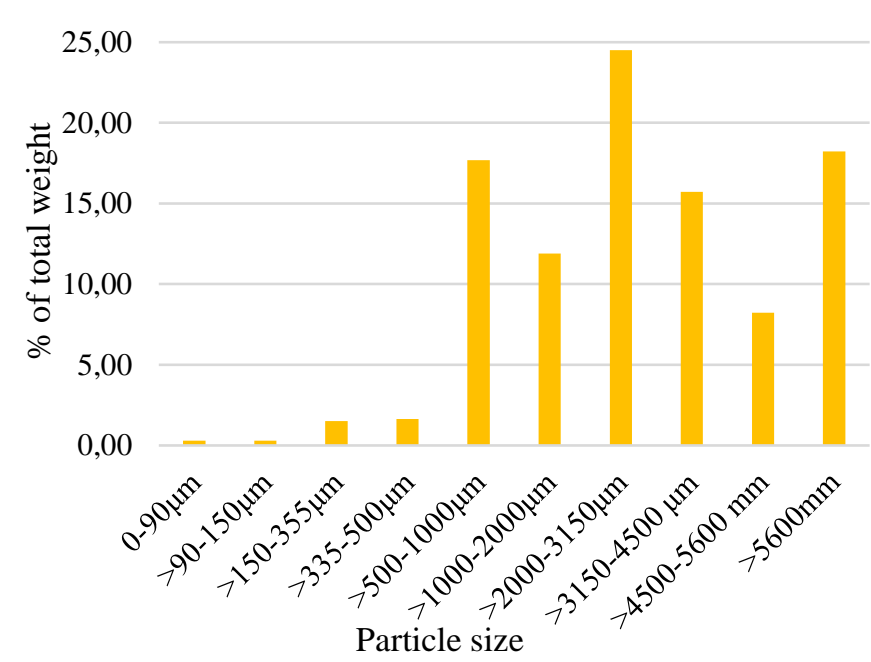

Figure 4. Distribution of particle masses.
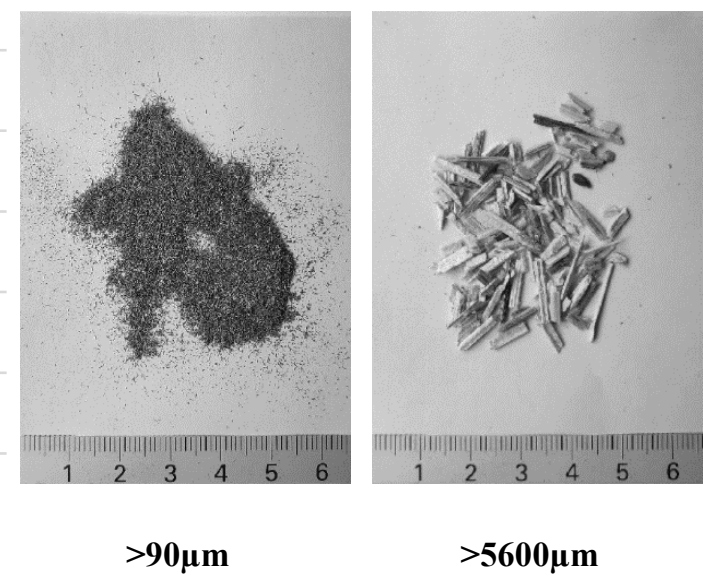

$>5600 \mu \mathrm{m}$

Figure 5. Hemp shive particle sizes.

\subsection{Thermal conductivity}

The density of the 200x200 mm sample of the manufactured board is $290 \mathrm{~kg} / \mathrm{m}^{3}$. Thermal conductivity of the board samples changed within the range from 0.064 to $0.074 \mathrm{~W} / \mathrm{m} \mathrm{K}$. In the sample with added PCM, the thermal conductivity of the nano capsule is $4 \%$ lower than that of a hemp board, $10 \%$ better than that of a preserved hemp-shives mixture board (Fig. 6). In the tests performed, it can be observed that if the density is $2 \%$ lower, then the coefficient of heat conduction is $4 \%$ better. To put it simpler, in this case the increase in conductivity is determined by the decrease in the porosity of the insulating material. Thermal conductivity for similar unconventional natural raw materials is in range 0.06 to 0.1 $\mathrm{W} / \mathrm{m} \mathrm{K}[30,31,32,33]$ that is very close to the measured values. 


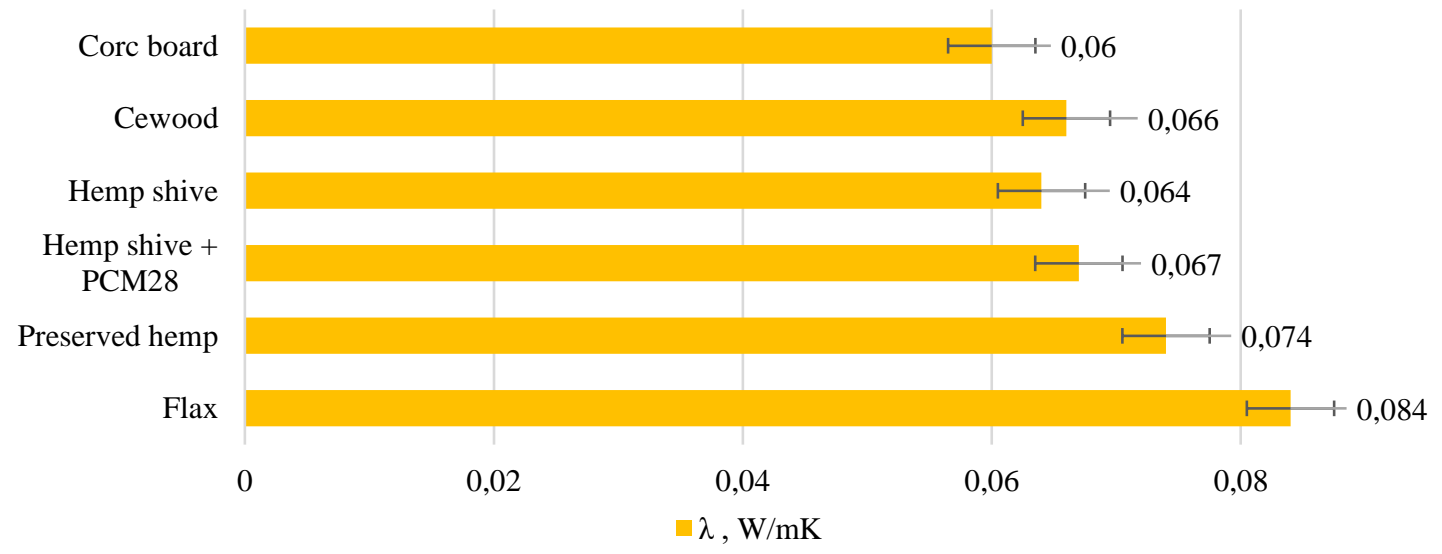

Figure 6. Thermal conductivity of experimental and reference boards [30,31,32,33].

\subsection{Specific heat capacity}

The experimental boards were made $25 \mathrm{~mm}$ thick with a density of $310 \pm 20 \mathrm{~kg} / \mathrm{m}^{3}$ that qualify them as low density boards. Another important performance indicator is high specific heat capacity. This property can be beneficial in buffering indoor temperature - during the summer it can reduce the need for cooling. As seen in Fig. 7, the specific heat of the experimental materials in the range of $1.4-1.8 \mathrm{~J} / \mathrm{g}$ $\mathrm{K}$ and it is mainly influenced by the quantity of the components of the material. The highest value of material specific heat is for hemp shive with integrated encapsulated phase change material and this value is $28 \%$ higher than material without phase change material. Specific heat capacity for similar unconventional natural raw materials is in the range of $1.28-2.1 \mathrm{~J} / \mathrm{g} \mathrm{K}[30,31,32,33]$, that is very close to the measured values.

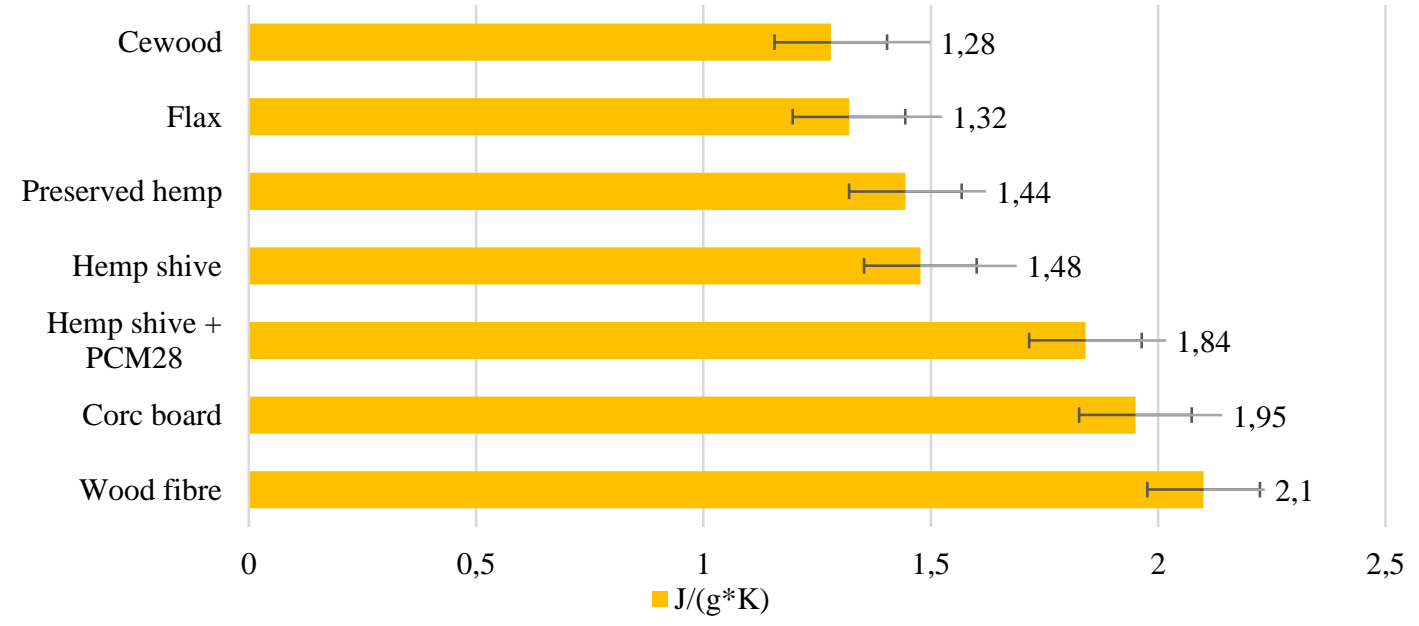

Figure 7. Specific heat capacity of experimental and reference boards [30,31,32,33].

The heat capacity at $35{ }^{\circ} \mathrm{C}$ on a NETZSCH equipment is determined by measuring the amount of heat that must be applied to a sample of material to raise its temperature from 30 to $40{ }^{\circ} \mathrm{C}$, i.e. by $10^{\circ} \mathrm{C}$. It is further used to determine the heat of phase transition. Applying this average calorific value to the entire $10{ }^{\circ} \mathrm{C}$ range, we obtain a calorific value of $15.5 \mathrm{~J} / \mathrm{g}$. Since the heat capacity changes little and practically linearly with temperature, such assumption is appropriate. There is also a phase transition between $20{ }^{\circ} \mathrm{C}$ and $30{ }^{\circ} \mathrm{C}$ so the amount of heat supplied in this temperature range is $28 \%$ higher than the heat capacity of the material alone. The measured heat input between $20^{\circ} \mathrm{C}$ and $30^{\circ} \mathrm{C}$ is $1.846 \mathrm{~J} / \mathrm{g} \mathrm{K}$. The difference between the amounts of heat determined by interpolation and those measured in this interval thus arises due to the change of phases. This difference is equal to $8200 \mathrm{~J} / \mathrm{kg}$. Given that $5 \% \mathrm{PCMs}$ are incorporated in the material sample, the phase change heat of the material is equal to $163 \mathrm{~J} / \mathrm{kg}$ only for PCM. 


\section{CONCLUSION}

For the first time, a thermal insulation material has been developed using hemp shives mass mixing phase change material microcapsule MikroCaps Ltd. The minimum volume for hemp shives is below $500 \mu \mathrm{m}$ that is $3.5 \%$ of the total weight, but it is dust that adversely affects the mechanical properties of the board. The production technology is simple and can be easily integrated into the traditional board production cycle, where additional mass mixing of PCM is required.

The thermal conductivity of the experimental samples is in the range of $0.064-0.067 \mathrm{~W} / \mathrm{m} \mathrm{K}$, that fits well in commercially available hemp insulation product class - i.e., falls within the thermal conductivity ranges of all generic groups of the insulation and is comparable with that of other fibrous insulation materials. As the material tests prove, the calorific value of the boards, in which 5\% encapsulate phase change material is mixed in the mass during the manufacturing process, has increased by $28 \%$ reaching $1.846 \mathrm{~J} / \mathrm{g} \mathrm{K}$. This property can be beneficial in buffering indoor temperature. Indeed, it can reduce the need for cooling during the summer.

The biggest problems could be the continuous supply of raw material throughout the year and the availability of hemp shives of the same quality from which to produce boards. It must be considered that hemp yields depend on external conditions and can only be grown seasonally in Europe, hence it becomes important to stock up hemp shives at the factory. Risks can arise during transport and installation of boards under incorrect operating conditions (created boards are intended for indoor use). Another factor may be the introduction of new requirements for thermal insulation materials and green materials in EU regulations / standards.

\section{Acknowledgment}

This work has been supported by the European Regional Development Fund within the Activity 1.1.1.2 "Post-doctoral Research Aid" of the Specific Aid Objective 1.1.1 "To increase the research and innovative capacity of scientific institutions of Latvia and the ability to attract external financing, investing in human resources and infrastructure" of the Operational Programme "Growth and Employment” (No. 1.1.1.2/VIAA/1/16/152)

\section{REFERENCES}

[1] Pacheco-Torgal F. Eco-efficient construction and building materials research under the EU Framework Programme Horizon 2020. Construction and Building Materials 2014, 51-162.

[2] Moreno B., Gonzalo FDA., Ferrandiz JA., Lauret B., Hernandez JA. A building energy simulation methodology to validate energy balance and comfort in zero energy buildings. Journal of Energy Systems 2019; 3: 168-182, DOI: $10.30521 /$ jes.623285

[3] Cuce E. Impacts of edge seal material on thermal insulation performance of a thermally resistive photovoltaic glazing: CFD research with experimental validation. Journal of Energy Systems 2019; 3: 26-35, DOI: 10.30521/jes.499794

[4] Wazna M E., Gounni A., Bouari AE., Alami ME., Cherkaoui O. Development, characterization and thermal performance of insulating nonwoven fabrics made from textile waste. Journal of Industrial Textiles 2018; 48: 1167-1183. DOI: $10.1177 / 1528083718757526$

[5] Cuce E., Cuce PM., Besir AB. Improving thermal resistance of lightweight concrete hollow bricks: A numerical optimisation research for a typical masonry unit. Journal of Energy Systems 2020; 4(3), 121-144. DOI: $10.30521 /$ jes. 775961

[6] Murphy DPL, Behring H, Wieland H. The use of flax and hemp materials for insulating. Proceedings of flax and other bast plants symposium 1997. 79-84.

[7] Kymalainen H. R., Sjoberg A.M. Flax and hemp fibres as raw materials for thermal insulations. Building and Environment 2008; 43: 1261-1269, DOI: 10.1016/j.buildenv.2007.03.006

[8] Kosan M., Akkoc A.E., Disili E., Aktas M. Design of an innovative PV/T and heat pump system for greenhouse heating. Journal of Energy Systems 2020; 4: 58-70, DOI: 10.30521/jes.740587 
[9] Lühr C., Pecenka R., Gusovius H.-J. Production of high-quality hemp shives with a new cleaning system. Agronomy Research 2015; 13(1): 130-140.

[10] Lühr C., Pecenka R., Budde J., Hoffmann T., Gusovius H-J. Comparative investigations of fiberboards resulting from selected hemp varieties. Industrial Crops \& Products 2018; 118: 81- 94. DOI: 10.1016/j.indcrop.2018.03.031

[11] Pecenka R., Fūrll C., Idler C., Grundmann P., Radosavljevic L. Fibre boards and composites from wet preserved hemp. Materials and Product Technology 2009; 36: 208-220.

[12] Ivanovs S., Rucins A., Valainis O., Belakova D., Kirilovs E., Vidzickis R. Research of technological process of hemp slab production, Engineering for rural development 2015, 202-209.

[13] Rofie S. Novel Low Density Particleboard from Hemp Shives, Doctoral Thesis. University of Wales, 2005.

[14] Lee S., Shupe T.F., Hse C.Y. Mechanical and physical properties of agro-based fiberboard. European Journal of Wood and Wood Products 2006. 74-79. ISSN 0018-3768.

[15] Zalba B., Marin J., Cabeza L.F., Mehling H. Review on thermal energy storage with phase change: materials, heat transfer analysis and applications. Applied Thermal Engineering 2003; 23: 251-283.

[16] Subramanian E. Integrating phase change materials in building materials: Experimentation, characterization and numerical simulation, Doctoral Thesis. Clemson University, 2011.

[17] Kuznik F., David D., Johannes K., Roux J-J. A review on phase change materials integrated in building walls. Renewable and Sustainable Energy Reviews 2011; 15 (1): 379-391, DOI: 10.1016/j.rser.2010.08.019

[18] Hawes D.W., Feldman D., Banu D. Latent heat storage in building materials. Energy and Buildings 1993; 20(1):77-86, DOI: 10.1016/0378-7788(93)90040-2

[19] Han X., Li Y., Yuan L., Wang Q, Zhang H., Lian H., Zhang G., \& Xiao L. Experimental study on effect of microencapsulated phase change coating on indoor temperature response and energy consumption. Advances in Mechanical Engineering 2017; 9(6): 1-8, DOI: 10.1177/168781401770390

[20] Rao Z., Wang S., Zhang Z. Energy saving latent heat storage and environmental friendly humidity-controlled materials for indoor climate. Renewable and Sustainable Energy Reviews 2012; 16: 3136- 3145. DOI: 10.1016/j.rser.2012.01.053

[21] Memon S. Phase change material sintegrated in building walls: A state of the art review. Renewable and Sustainable Energy Reviews 2014; 31: 870-906, DOI: 10.1016/j.rser.2013.12.042

[22] Al-Absi Z.A., Mohd Isa M.H., Ismail M. Phase Change Materials (PCMs) and Their Optimum Position in Building Walls. MDPI Sustainability 2020; 12(4): 1-25, DOI: 10.3390/su12041294

[23] Sun X., Jovanovic J., Zhang Y., Fan S., Chu Y., Mo Y., Liao S. Use of encapsulated phase change materials in lightweight building walls for annual thermal regulation. Energy 2019; 180: 858-872, DOI: 10.1016/j.energy.2019.05.112

[24] Santos-Herrero, J.M., Lopez-Guede, J.M., Flores, I., A Short review on the use of renewable energies and model predictive control in buildings, Journal of Energy Systems 2017; 1(3): 112-120 DOI: $10.30521 /$ jes. 346653

[25] LVS EN 322:1993. Wood-based panels - Determination of moisture content.

[26] LVS EN 933-1:2012. Tests for geometrical properties of aggregates - Part 1: Determination of particle size distribution - Sieving method.

[27] Zarei A. Characterization of szego-milled hemp fibres. [Doctoral Thesis], University of Toronto, 2010.

[28] LVS EN 323:2000. Wood-based panels - Determination of density.

[29] LVS ISO 8302: 2001. Thermal insulation - Determination of steady-state thermal resistance and related properties-Guarded Hot Plate apparatus.

[30] Gendelis S., Jakovičs A., Engelhardt M., Thermal and moisture adsorption/desorption properties for a selection of vegetal insulation materials. 4th Central European Symposium on Building Physics, MATEC Web Conference 2019. 1-5.

[31] Kozlowski R., Wladyka-Przybylak M. Uses of natural fiber reinforced plastics. In: Wallenberger F.T and Weston N. Natural fibres, plastics and composites. Springler, 2004; 249-262.

[32] Pfundstein M., Gellert R., Spitzner M., Rudolphi A. Insulating Materials: Principles, Materials, Applications. Regensburg: Aumüller Druck, 2008.

[33] Lekavicius V., Shipkovs P., Ivanovs S., Rucins A. Thermo-Insulation Properties Of Hemp-Based Products. Latvian Journal of Physics and Technical Sciences 2015; 52: 38-51, DOI: 10.1515/lpts-2015-0004 